\title{
Hepatoprotective effects of ginseng saponins in a mouse model of carbon tetrachloride-induced liver injury
}

\author{
Huizhi Lu, Yun Tan, Luyu Yang, Hui Dong, Youxia Liao, Song Cao, Shouzhi Fu* \\ Department of Critical Care Medicine and Emergency, Tongren Hospital, Wuhan, Hubei, P.R. China, 430074
}

*For correspondence: Email: Fushouhzi586@126.com

Sent for review: 22 August 2018

Revised accepted: 17 November 2018

\begin{abstract}
Purpose: To investigate the effects of ginsenosides $\mathrm{Rg} 1$ and $\mathrm{Rb} 1$ on carbon tetrachloride $\left(\mathrm{CCl}_{4}\right)$ induced liver injury in mice.

Methods: Thirty-two mice were randomly divided into four groups. In control group, mice were administered sodium carboxymethylcellulose (CMC-Na) by intraperitoneal injection for seven days. In $\mathrm{CCl}_{4}$ treatment group, mice were treated as control group for the first seven days and then intraperitoneally injected with $\mathrm{CCl}_{4}$ in olive oil on day 8. In Rb1-and Rg1-treatment group, the mice were intraperitoneally injected with $\mathrm{Rb} 1$ or $\mathrm{Rg} 1$ (each $30 \mathrm{mg} / \mathrm{kg}$, dissolved in $0.5 \% \mathrm{CMC}-\mathrm{Na}$ ), respectively for seven days, followed by intraperitoneal injection with $\mathrm{CCl}_{4}$ in olive oil on day 8 . Histological damage was examined by haematoxylin and eosin (H\&E) staining. Serum levels of alanine aminotransferase (ALT) and aspartate transaminase (AST) were assessed enzymatically. Tissue IL-6 and IL-8 levels were measured by ELISA. Gene and protein levels of transforming growth factor (TGF)- $\beta$, Smad2, and Smad3 were analyzed by real-time PCR (RT-PCR) and western blotting, respectively.

Results: $\mathrm{CCl}_{4}$ treatment caused histological damage in mouse liver, and increased the levels of $A L T$, AST (five-fold), IL-6 (three-fold), and IL-8 (five-fold), and elevated expressions of TGF- $\beta$, Smad2, and Smad3. Ginsenosides Rg1 or Rb1 pre-treatment attenuated liver injury by decreasing the serum levels of $A L T$ (from 700 to $200 \mathrm{UI} / \mathrm{L}$ ) AST (from $550 \mathrm{pg} / \mathrm{mL}$ to $250 \mathrm{pg} / \mathrm{ml}$ ), IL-6 (from 1,100 to $750 \mathrm{pg} / \mathrm{mL}$ ), and IL-8 (from 600 to $200 \mathrm{pg} / \mathrm{mL}$ ), and inhibiting the expressions of TGF- $\beta$, Smad2, and Smad3.

Conclusion: Ginsenosides (Rg1 and $\mathrm{Rb} 1$ ) attenuate $\mathrm{CCl}_{4}$-induced liver injury and inflammation by regulating TGF- $\beta / S m a d$ signalling pathway.
\end{abstract}

Keywords: Ginseng saponin, Ginsenosides, Rg1, Rb1, Hepatoprotective effect, TGF- $\beta /$ Smad signalling pathway

\begin{abstract}
This is an Open Access article that uses a funding model which does not charge readers or their institutions for access and distributed under the terms of the Creative Commons Attribution License (http://creativecommons.org/licenses/by/4.0) and the Budapest Open Access Initiative (http://www.budapestopenaccessinitiative.org/read), which permit unrestricted use, distribution, and reproduction in any medium, provided the original work is properly credited.

Tropical Journal of Pharmaceutical Research is indexed by Science Citation Index (SciSearch), Scopus, International Pharmaceutical Abstract, Chemical Abstracts, Embase, Index Copernicus, EBSCO, African Index Medicus, JournalSeek, Journal Citation Reports/Science Edition, Directory of Open Access Journals (DOAJ), African Journal Online, Bioline International, Open-J-Gate and Pharmacy Abstracts
\end{abstract}

\section{INTRODUCTION}

The liver, an important metabolic organ, plays a key role in many physiological processes, including clearance of drugs and toxins, protein synthesis, and nutrient metabolism [1,2]. Liver injury is a common consequence of various diseases, and acute hepatic failure is known to affect human health worldwide [3]. Liver injury caused by toxin-induced metabolic dysfunction often leads to inflammation, or even hepatic fibrosis [4]. Carbon tetrachloride $\left(\mathrm{CCl}_{4}\right)$, a potent chemical hepatotoxin, has been widely used in animal models of liver injury accompanied by 
inflammation and fibrosis. The metabolism of $\mathrm{CCL}_{4}$ can yield reactive free radicals which increase lipid peroxidation and protein oxidation, leading to liver injury [5].

The ginsenosides $\mathrm{Rg} 1$ and $\mathrm{Rb} 1$, two primary active compounds from Panax ginseng $C$. A. Mey, have been reported to elicit pharmacological effects, such as immunoregulation, neuroprotection, and hepatoprotection [6,7]. Many studies have demonstrated that ginsenosides can function as hepatoprotective agents in multiple models of hepatic injury and other diseases [6,7]. However, the protective mechanism of $\mathrm{Rg} 1$ and $\mathrm{Rb} 1$ in $\mathrm{CCl}_{4}$-induced liver injury is still unclear. In this study, the effects of Rg1 and Rb1 in a model of $\mathrm{CCl}_{4}$-induced acute liver injury was explored, noting changes in tissue histology and cytokine levels. The hepatoprotective mechanism of Rg1 and $R b 1$ was investigated in detail.

\section{EXPERIMENTAL}

\section{Materials}

Ginsenosides $\mathrm{Rg} 1$ and $\mathrm{Rb} 1$ were purchased from Sigma-Aldrich (St Louis, MO, USA). The enzymatic kits for alanine aminotransferase (ALT) and aspartate transaminase (AST) were purchased from Nanjing Jiancheng Bioengineering Research Institute (Nanjing, China). All primary antibodies were purchased from Cell Signaling Technology, Inc. (Beverly, MA). All primers were purchased from Shanghai Sangon Biological Engineering Co., Ltd. (Shanghai, China). TNF- $\alpha$ and IL-6 ELISA kits were purchased from R\&D Systems Inc. (Minneapolis, MN, USA).

\section{Liver injury model}

Male ICR mice, purchased from Vital River Laboratory Animal Technology Co., Ltd. (Beijing, China), were housed at $23^{\circ} \mathrm{C}$, given free access to food and water. All animal experiments were performed in accordance with Guide for the Care and Use of Laboratory Animals [8] and approved by the animal ethics committee of Wuhan Third Hospital (approval no. KY2018-026). Acute liver injury was induced by $\mathrm{CCl}_{4}$. Thirty-two mice were randomly divided into four groups (control, $\mathrm{CCl}_{4}$, $\mathrm{Rg} 1$, and Rb1). Control mice were administered sodium carboxymethylcellulose (CMC-Na, $0.5 \%$, the same volume used for the $\mathrm{Rg} 1$ and $\mathrm{Rb} 1$ groups) by intraperitoneal injection for seven days. $\mathrm{CCl}_{4}$-treated mice were treated like the controls for the first seven days and then intraperitoneally injected with $\mathrm{CCl}_{4}[10 \mathrm{mg} / \mathrm{kg}$ $(\mathrm{v} / \mathrm{v})$ in $0.3 \%$ olive oil] on day 8. Rb1- and Rg1- treated mice were intraperitoneally injected with $\mathrm{Rb} 1$ and $\mathrm{Rg} 1$ (each $30 \mathrm{mg} / \mathrm{kg}$, dissolved in $0.5 \%$ $\mathrm{CMC}-\mathrm{Na}$ ), for seven days and then intraperitoneally injected with $\mathrm{CCl}_{4}[10 \mathrm{mg} / \mathrm{kg}$ $(\mathrm{v} / \mathrm{v})$ in $0.3 \%$ olive oil] on day 8 . After $24 \mathrm{~h}$, all mice were sacrificed by cervical vertebra disjointing, liver and blood samples were collected for further analysis.

\section{Haematoxylin and eosin (H\&E) staining of mouse liver}

The left lobes of mouse liver were washed with phosphate buffer saline then were fixed in formalin $(0.4 \%)$ for haematoxylin and eosin (H\&E) staining. After dehydration in graded alcohol, the tissue was embedded in paraffin and cut into 3 to $4 \mu \mathrm{m}$ sections on a Leica SM2010 R Sliding Microtome (Leica, Buffalo Grove, IL, USA). The sections were then deparaffinized, rehydrated, and stained with hematoxylin-eosin for $5 \mathrm{~min}$ at $37^{\circ} \mathrm{C}$. Finally, the sections were mounted in neutral Canada balsam after dehydration, observed by optical microscopy, and evaluated by pathologists, blind to the identity of the sections.

\section{Analysis of serum ALT and AST levels}

Blood was centrifuged at $3000 \mathrm{rpm} / \mathrm{min}$ for $5 \mathrm{~min}$, and the serum was analyzed for ALT (C009-2) and AST (C010-2) levels using commercial ELISA kits according to the manufacturer's protocol.

\section{Determination of liver TNF- $\alpha$ and ILG6 levels}

Mouse livers were rinsed in saline. One lobe of the liver was rinsed in saline $[1: 9(\mathrm{~m} / \mathrm{v})]$, and homogenized in ice-cold Nonidet P 40 (NP-40) using a glass homogenizer. TNF- $\alpha$ and ILQ 6 levels in liver homogenates were measured by ELISA, according to the manufacturer's instructions.

\section{Western blotting}

Liver tissues were homogenized in RIPA buffer, and proteins were quantified using the BCA method (Thermo Scientific, Rockford, IL, USA). Equal amounts of protein were loaded and separated on a $10 \%$ SDS-polyacrylamide gel and transferred onto a PVDF membrane (Millipore, MA). After blocking, the membranes were incubated with respective primary antibodies [TGF $\beta$ (\#79424), Smad2 (\#5339), and Smad3 (\#9523) at a 1:1,000 dilution] and secondary antibodies (1:10,000 dilution). The proteins were detected by chemiluminescence and quantified using ImageJ software. 
Real-time reverse transcription-polymerase chain reaction (RT-PCR)

Total liver RNA was extracted using TRIzol reagent (Invitrogen) and reverse-transcribed into cDNA using the GoScript ${ }^{\mathrm{TM}}$ Reverse Transcription System (Promega). Quantitative RT-PCR was performed using the SYBR Green PCR Master Mix reagent kit (Promega). The primers used for RT-PCR were described previously [9].

\section{Statistical analysis}

Statistical analysis was performed using one-way ANOVA or Tukey's test by SPSS software (Chicago, IL, USA) Data are presented as mean \pm standard deviation (SD), with $p<0.05$ was considered statistically significant.

\section{RESULTS}

\section{Histopathological features}

Histological changes in the liver were observed by H\&E staining. As shown in Figure 1, Liver from control mice (Figure 1A) had clear lobules and regular cord structures, whereas livers from $\mathrm{CCl}_{4}$-treated mice showed apparent pathological changes, including vacuoles (arrows) and necrosis, indicative of severe liver damage (Figure 1B). Pre-treatment with Rg1 (Figure 1C) or Rb1 (Figure 1D) attenuated the severity of liver injury, with a corresponding decrease in the number of vacuoles with no apparent necrosis.
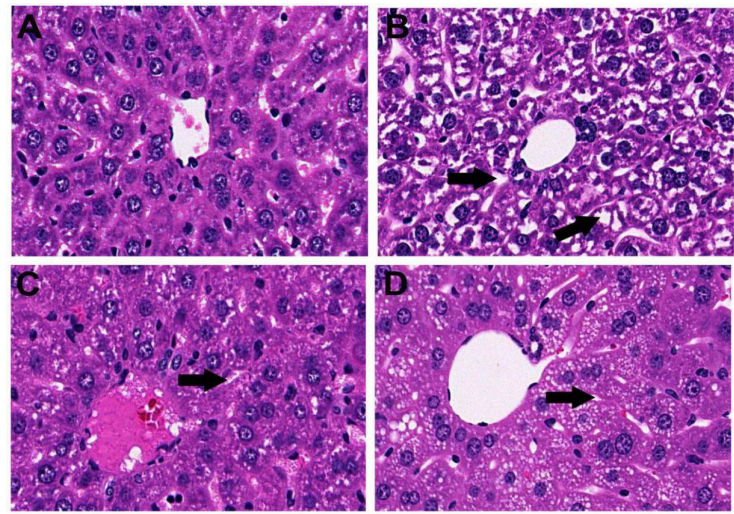

Figure 1: Liver histopathology (H\&E staining). A, control group; $\mathrm{B}, \mathrm{CCl}_{4}$ group; $\mathrm{C}, \mathrm{Rg} 1$ group; $\mathrm{D}, \mathrm{Rb} 1$ group. Arrows indicated vacuoles areas and necrosis areas

\section{Effects of Rg1 and Rb1 on ALT and AST levels}

As shown in Figure 2, ALT levels in the $\mathrm{CCl}_{4}$ group were about 2.5 times higher than in the control group, and AST levels were present at five-fold higher levels than in the control group. ALT and AST levels in Rg1- or Rb1-treated mice decreased significantly when compared with the $\mathrm{CCl}_{4}$ group. These results are in accordance with the histopathological results.
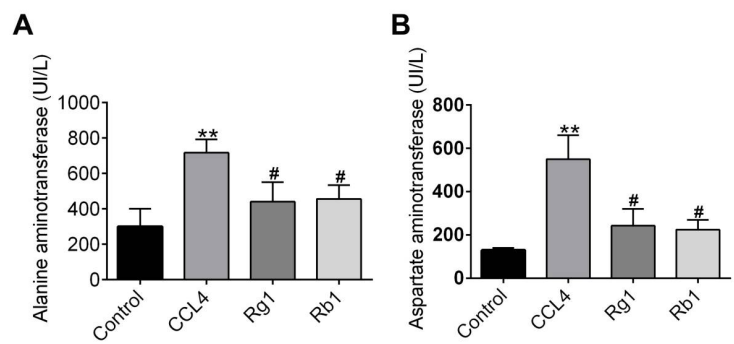

Figure 2. Serum ALT (A) and AST (B) levels in $\mathrm{CCl}_{4-}$ induced mice; $\mathrm{n}=8,{ }^{* *} p<0.01$ vs. control, ${ }^{\sharp} p<0.5$ vs. $\mathrm{CCl}_{4}$

\section{Effects of Rg1 and Rb1 on liver cytokine expression levels}

Proinflammatory cytokines, such as IL-6 and IL8 , are crucial mediators contributing to the development of liver inflammation. The effects of $\mathrm{Rg} 1$ and $\mathrm{Rb} 1$ on $\mathrm{IL}-6$ and $\mathrm{IL}-8$ levels in $\mathrm{CCl}_{4}-$ treated mice were investigated, and the results are shown in Figure 3. IL-6 levels in the $\mathrm{CCl}_{4}$ group was about three-fold higher than in the control group, and IL-8 levels were five-fold higher than in the control group. IL-6 and IL-8 levels decreased significantly after Rg1 and Rb1 pre-treatment when compared with the $\mathrm{CCl}_{4}$ group, which indicate that $\mathrm{Rg} 1$ and $\mathrm{Rb} 1$ attenuate inflammation induced by liver damage.

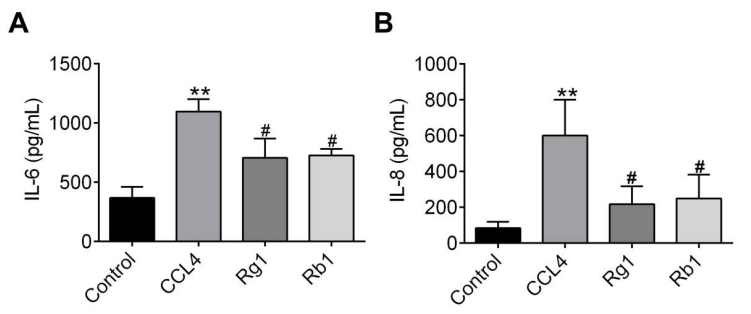

Figure 3: Liver IL-6 (A) and IL-6 (B) levels in $\mathrm{CCl}_{4^{-}}$ induced mice; $\mathrm{n}=8,{ }^{* *} p<0.01$ vs. control, ${ }^{\#} p<0.5$ vs. $\mathrm{CCl}_{4}$

\section{Effects of Rg1 and Rb1 on the TGF- $\beta /$ Smad signalling pathway}

As shown in Figure 4, TGF- $\beta$, Smad2, and Smad3 levels were increased in $\mathrm{CCl}_{4}$ group compared with control group. Pre-treatment with Rg1 or Rb1 blocked the high expression of TGF$\beta$, Smad2, and Smad3 induced by $\mathrm{CCl}_{4}$, which indicates that $\mathrm{Rb} 1$ and $\mathrm{Rg} 1$ can attenuate liver injury induced by $\mathrm{CCl}_{4}$ by regulating the TGF$\beta /$ Smad signalling pathway.

Trop J Pharm Res, December 2018; 17(12): 2383 
A

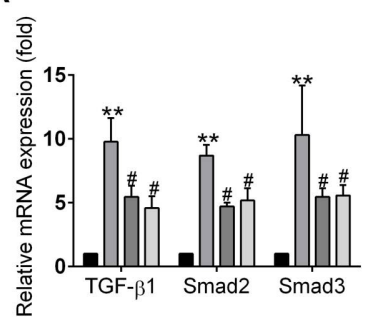

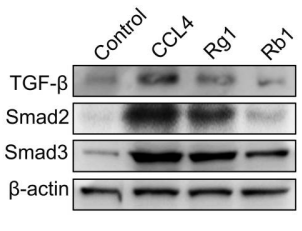

Figure 4: Gene $(A)$ and protein $(B)$ expression levels of TGF- $\beta$, Smad2, and Smad3; $\mathrm{n}=8,{ }^{* *} p<0.01$ vs. control, ${ }^{\#} p<0.5$ vs. $\mathrm{CCl}_{4}$

\section{DISCUSSION}

The liver is an important metabolic organ. Liver injury causes inflammation, which can contribute to various pathological events [10]. As a wellknown hepatotoxin that gives rise to free radicals, $\mathrm{CCl}_{4}$ is widely used in liver injury models. Trichloromethyl radical, the metabolite of $\mathrm{CCl}_{4}$, causes lipid peroxidation which can activate Küpffer cells and trigger the production of inflammatory cytokines [11,12]. $\mathrm{CCl}_{4}$-induced liver injury is believed to mimic the liver damage caused by various toxins in humans [13].

Inflammation and oxidative stress are closely related to liver injury and fibrosis. Many studies have demonstrated that anti-inflammatory and oxidative agents such as epigallocatechin-3gallate, are able to significantly attenuate the severity of $\mathrm{CCl}_{4}$-induced liver injury and fibrosis [14]. A previous study demonstrated that ginseng essence extracted from four medicinal, edible herbs $(P$. ginseng, Panax quinquefolius, Nelumbo nucifera, and Lilium longiflorum), can attenuate $\mathrm{CCl}_{4}$-induced liver inflammation and fibrosis by inhibiting oxidative stress [15]. The two compounds in this study, Rg1 and Rb1, are the two primary active compounds in $P$. ginseng C. A. Mey. The current study showed that Rg1 and $\mathrm{Rb} 1$ attenuated the severity of $\mathrm{CCl}_{4}$-induced liver injury and regulate inflammation and fibrosis.

TGF- $\beta$, the main fibrogenic cytokine produced by Küpffer and stellate cells in the liver, was overexpressed in $\mathrm{CCl}_{4}$-induced liver injury in mice. Activation of the TGF receptor leads to the phosphorylation of Smad2 and Smad3 $[16,17]$. Results of previous studies found that blocking TGF- $\beta$ signalling significantly protect rats from toxin-induced liver fibrosis $[18,19]$. The results of this study indicate that $R g 1$ and $R b 1$ inhibit the TGF- $\beta /$ Smad signalling pathway and attenuate liver injury and fibrosis. Moreover, In addition, further studies about the precise mechanism of the association between inflammation and

fibrosis are also needed. Such research will allow a better understanding of the hepatoprotective effects of ginsenosides and provide guidance for their clinical use.

\section{CONCLUSION}

The results of this study indicate that $\mathrm{Rg} 1$ and $\mathrm{Rb} 1$ attenuate $\mathrm{CCl}_{4}$-induced liver injury and inflammation by regulating TGF- $\beta / S m a d$ signalling pathway, suggesting the potential value of ginsenosides in clinical management of liver inflammation.

\section{DECLARATIONS}

\section{Acknowledgement}

This work was funded by Wuhan Health and Family Planning Commission Project (no. WX18D18).

\section{Disclosure of interest}

The authors declare that no conflict of interest is associated with this work.

\section{Contribution of authors}

We declare that this work was done by the authors named in this article and all liabilities pertaining to claims relating to the content of this article will be borne by the authors. Huizhi Lu and Yun Tan designed all the experiments and revised the paper. Luyu Yang, Hui Dong, Youxia Liao and Song Cao performed the experiments, Shouzhi Fu wrote the paper.

\section{REFERENCES}

1. Dwivedi $S$, Khatri $P$, Rajwar $S$, Dwivedi $A$. Pharmacognostic and pharmacological aspects of potent herbal hepatoprotective drugs- $A$ review. International Journal of Research in Pharmaceutical and Biomedical Sciences 2011; 2:492-499.

2. Protzer U, Maini MK, Knolle PA. Living in the liver: hepatic infections. Nat Rev Immunol 2012; 12:201-213.

3. Browning JD, Horton JD. Molecular mediators of hepatic steatosis and liver injury. J Clin Invest 2004; 114:147152.

4. Sun $H$, Chen L, Zhou W, Hu L, Li L, Tu Q, Chang Y, Liu $Q$, Sun $X, W u M$ et al. The protective role of hydrogenrich saline in experimental liver injury in mice. J Hepatol. 2011; 54(3): 471-480.

5. Abdelaziz DH, Ali SA. The protective effect of Phoenix dactylifera $L$. seeds against CCl4-induced hepatotoxicity in rats. J Ethnopharmacol 2014; 155:736-743.

Trop J Pharm Res, December 2018; 17(12): 2384 
6. Leung KW, Wong AS. Pharmacology of ginsenosides: a literature review. Chin Med 2010; 5:20.

7. Ahmed T, Raza SH, Maryam AN.Setzer W. Ginsenoside $R b 1$ as a neuroprotective agent: $A$ review. Brain Res Bull 2016; 125:30-43.

8. Council NR.Guide for the Care and Use of Laboratory Animals: National Academies Press; 2010.

9. Tao T, Chen F, Bo L, Xie Q, Yi W, Zou Y, Hu B, Li J, Deng $X$. Ginsenoside Rg1 protects mouse liver against ischemia-reperfusion injury through anti-inflammatory and anti-apoptosis properties. Journal of Surgical Research. 2014; 91(1): 231-238.

10. Luedde T, Schwabe RF. NF-KB in the liver-linking injury, fibrosis and hepatocellular carcinoma. NatRev Gastroenterol Hepatol 2011; 8:108-118

11. Luckey SW, Petersen DR. Activation of Kupffer cells during the course of carbon tetrachloride-induced liver injury and fibrosis in rats. Exp Mol Pathol 2001; 71:226240.

12. Lee CH, Park SW, Kim YS, Kang SS, Kim JA, Lee SH, Lee SM. Protective mechanism of glycyrrhizin on acute liver injury induced by carbon tetrachloride in mice. Biol Pharm Bull. 2007; 30(10): 1898-1904.

13. Muriel P. Nitric oxide protection of rat liver from lipid peroxidation, collagen accumulation, and liver damage induced by carbon tetrachloride. Biochem Pharmacol 1998; 56:773-779.

14. Tipoe GL, Leung TM, Liong EC, Lau TY, Fung ML, Nanji $A A$. Epigallocatechin-3-gallate (EGCG) reduces liver inflammation, oxidative stress and fibrosis in carbon tetrachloride (CCl4)-induced liver injury in mice. Toxicol 2010; 273:45-52.

15. Lu KH, Weng CY, Chen WC, Sheen LY. Ginseng essence, a medicinal and edible herbal formulation, ameliorates carbon tetrachloride-induced oxidative stress and liver injury in rats. J Ginseng Res 2017; 41:316-325.

16. SD K, WA B. Liver fibrosis and inflammation. A review. Annals Hepatol 2003; 2:159-163.

17. Gressner AM, Weiskirchen R, Breitkopf K, Dooley S. Roles of TGF-beta in hepatic fibrosis. Front Biosci 2002; 7:d793-807.

18. Gouville A-Cd, Boullay V, Krysa G, Pilot J, Brusq J-M, Loriolle $F$. Inhibition of TGF- $\beta$ signaling by an ALK5 inhibitor protects rats from dimethylnitrosamine-induced liver fibrosis. Bri J Pharmacol 2005; 145.

19. Gressner AM, Weiskirchen R. Modern pathogenetic concepts of liver fibrosis suggest stellate cells and TGF$\beta$ as major players and therapeutic targets. J Cell Molecular Med 2006; 10:76-99. 